\title{
8 FACES DA TURQUIA: UM PARALELO COM MINHA VIDA NA TURQUIA Resenha sobre a série turca "8 em Istambul” (Netflix)
}

\author{
Por Mustafa Göktepe ${ }^{1}$
}

FICHA TÉCNICA

Direção e roteiro: Berkun Oya

Exibição: Netflix

Duração: 1 temporada, 8 episódios de aprox. 50 min. cada

Classificação: 16 anos

País: Turquia

Gêneros: Drama, suspense, série

\footnotetext{
1 Naturalizado brasileiro, nato turco, casado com brasileira, pai de duas filhas, residente no Brasil desde 2004. Fundador e presidente do Instituto pelo Diálogo Intercultural, uma ONG brasileira com atuação acadêmica, cultural e social em São Paulo, Brasília e no Rio de Janeiro. Professor visitante de Língua e Cultura Turca na Universidade de São Paulo (USP), desde 2010. Professor visitante de Civilização Turco-islâmica na Universidade Católica de São Paulo (PUC-SP), de 2009 a 2013. Professor de Língua Turca na Universidade de Brasília (UnB) de 2013 a 2014. Tradutor juramentado (AD-HOC) de turco-português na Junta Comercial do Estado de São Paulo (JUCESP) e Junta Comercial do Distrito Federal (JCDF). Tradutor e revisor de livros, filmes, novelas e documentários. Intérprete profissional. Sócio proprietário da rede de restaurante de delivery de comidas turcas "Lahmajun - Delícias Turcas" em São Paulo, Brasil. Link para o Currículo Lattes: http://lattes.cnpq.br/8569681553122469. ORCID ID: https://orcid.org/0000-0002-2517-1346. Contato: mustafa@institutopelodialogo.org.br.
} 


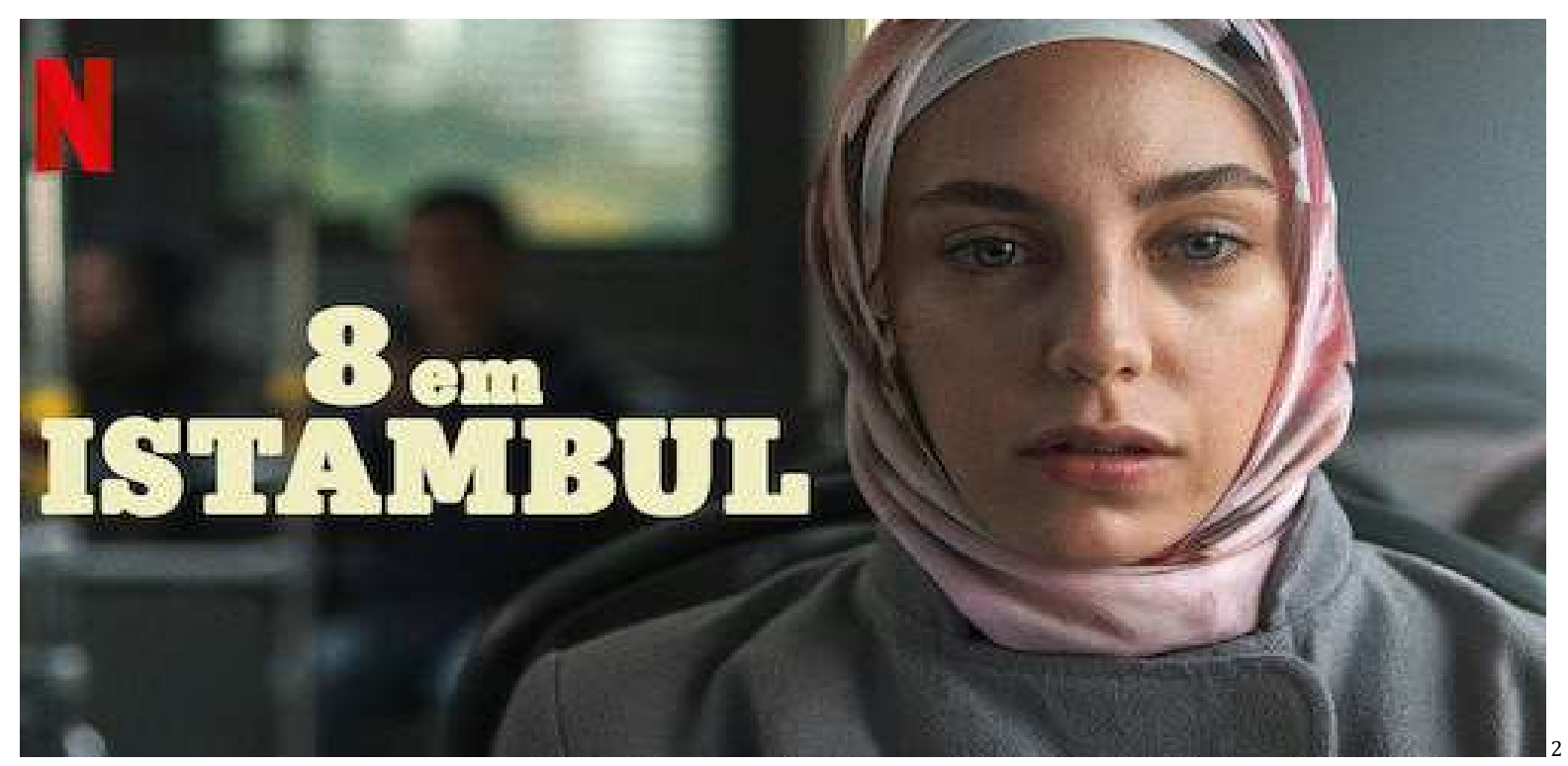

Sendo eu um turco (naturalizado brasileiro) que vive no Brasil há 17 anos, e que não pode viajar à Turquia desde $2016^{3}$, passei por muitos sentimentos e emoções, principalmente nostalgia e saudade, ao assistir "8 em Istambul" ("Bir Baskadir" em turco e "Ethos" em inglês). Os diferentes grupos socioculturais da sociedade turca e a interação entre eles estão muito bem apresentados nesse drama lançado mundialmente pela Netflix em novembro de 2020, com oito episódios de aproximadamente 50 minutos. Por isso, ao longo da resenha traçarei paralelos dos personagens com a minha vida e família, como turcos e enquadrados em alguns desses diferentes grupos socioculturais da sociedade turca.

O nome em português faz menção a oito principais personagens da série: cada uma representando uma face da sociedade turca: Meryem, Sinan, Peri, Gülbin, Yasin, Ali Sadi Hodja, Hayrunnisa, Hilmi. É claro que elas não esgotam as possibilidades de grupos sociais na Turquia, mas certamente retratam boa parte deles.

0 personagem principal, Meryem ${ }^{4}$ (Öykü Karayel), que ilustra o cartaz do drama, representa "a maioria" da sociedade turca, principalmente do interior, na Anatólia, a parte asiática da Turquia: humilde, trabalhadora, respeitadora das tradições e dos pontos essenciais da religião. Meryem é um retrato das mulheres que não tiveram a oportunidade de estudar, viajar, conhecer o mundo. Fazem diversos sacrifícios para viver dignamente: cozinham, limpam e arrumam a casa, cuidam das crianças e algumas, inclusive, trabalham

\footnotetext{
2 Fonte da imagem: https://interprete.me/wp-content/uploads/2020/11/8-em-istambul-netflix-serie-drama-turco-0.jpg

3 Eu sou um membro do Movimento Hizmet. O Hizmet ("serviço” na língua turca), é uma iniciativa civil mundial, enraizada na tradição espiritual e humanística do Islam, inspirado pelas ideias e ativismo do erudito turco Fethullah Gülen. É um movimento social, cultural e educacional, cujos princípios básicos decorrem dos valores humanos universais, como o amor pela criação, respeito às diferenças, empatia pelo ser humano, compaixão e altruísmo. Fethullah Gülen é um teólogo turco, literato, pensador, escritor, poeta, líder de opinião, ativista pela educação, defensor da paz, considerado como um influente erudito muçulmano. (Cf. informações oficiais presentes no site do movimento e do Fethullah Gulen, respectivamente: www.movimentohizmet.com.br. e https://fgulen. $\mathrm{com} / \mathrm{pt}$.

4 Meryem é Maria em turco, que se refere à mãe de Jesus. Jesus (Isa, em turco e árabe) é considerado um profeta que nasceu milagrosamente, sendo a sua mãe, Maria, virgem. É a única mulher que tem uma das 114 suratas (capítulos do Alcorão, o livro sagrado dos muçulmanos) em seu nome, no qual é narrada a sua história e a de Jesus. Na Turquia, há mais de 300 mil mulheres com esse nome.
} 
fora com faxina ou outros serviços.

Fazendo um paralelo da personagem com minha família, digo que minha mãe é uma dessas Meryems. Ela nasceu e cresceu num vilarejo próximo à cidade de Beysehir, na província de Konya, região central da Turquia. Trabalhou desde a sua infância nos campos de plantação de trigo, grão-de-bico, legumes e frutas, cuidou das hortas, vacas e ovelhas. Por ser obrigatório, ela foi à escola para estudar o equivalente ao Fundamental I, porém, esse estudo foi interrompido por causa de um incêndio em sua casa, o qual queimou grande parte do corpo dela. Ainda criança, passou meses no hospital, em outra província, longe de sua família. Lembro-me de que ela me contava que, apesar de quase analfabeta, escreveu poesias sobre a solidão que sentia naquele hospital - e, mais tarde, teve que aprender a ler e a escrever sozinha, já que não conseguiu completar sua educação.

Anos depois, ela deu à luz a mim, em casa mesmo, naquele vilarejo de Konya, com parteiras voluntárias, e em alguns dias voltou aos trabalhos na colheita, me carregando amarrado em suas costas. Deu à luz as minhas duas irmãs da mesma forma. Eu cresci nesse ambiente, também começando a trabalhar no campo ainda na infância. Estudei na escola da aldeia até os 10 anos. Mas meus pais, que não queriam essa vida para mim e para minhas irmãs, decidiram se mudar para Izmir (Esmirna), a terceira maior cidade da Turquia, no extremo Oeste do país, próxima às ilhas gregas no Mar Egeu; conhecida como a cidade mais ocidentalizada do país. Lá, meu pai alugou um apartamento e trabalhava como motorista com seu trator, que levara do vilarejo, numa obra pública de viadutos. Em poucos anos, a obra foi concluída e meu pai ficou desempregado. Foi aí que começamos a vender meias, camisetas e roupas, depois ovos, melancias e outras frutas, até que, por fim (e por muitos anos), batata e cebola, nas ruas e nas feiras de rua. Digo começamos, pois com 13 anos eu comecei a trabalhar com meu pai, empurrando um carrinho com os produtos que vendíamos e gritando para atrair os clientes. No entanto, chegou o momento em que não dava mais para pagar aluguel apenas com esse ganho. Por isso, meu pai acabou construindo nossa casinha, ele mesmo, com barro e tijolos que encontrou como sobras de grandes obras, num morro distante do centro urbano, num lugar parecido com as favelas brasileiras, onde não havia encanamento de água potável, fornecimento de energia, nem sistema de esgoto. Eu passei minha adolescência toda nessa casa, na qual estudei para o Ensino Médio e para o vestibular, muitas vezes à luz de velas: a energia foi fornecida pela prefeitura só alguns anos depois que nós construímos essa casinha.

Quando eu consegui ingressar na universidade, fui o primeiro do nosso vilarejo e da nossa família a ter esse êxito. Foi o maior orgulho para meus pais e para mim. Minha mãe me ensinou e motivou a ser trabalhador, não desperdiçar nada, estudar para não ter a vida difícil que eles tiveram. Minha mãe, como a Meryem de 8 em Istambul, sempre foi positiva, carregou muitos pesos nas costas e teve muitas doenças. Meryem e minha mãe representam uma grande parte das mulheres turcas.

No entanto, voltando à personagem do filme, Meryem não é casada, nem conseguiria planejar um casamento, pois se sacrifica para cuidar dos sobrinhos e do irmão, devido às condições de saúde ruins de sua cunhada. Meryem pensa, sente, mas não consegue e não tem com quem se expressar. Isso a afeta até o ponto de ter desmaios. Quando finalmente procura tratamento em hospitais, Meryem é diagnosticada com problema psíquico, por isso, começa a ter atendimento com uma psiquiatra num hospital público.

Em seu trabalho como faxineira, Meryem tem contato com o personagem Sinan (Ali 
Yücesoy), que representa "a maioria” entre a juventude de elite das grandes metrópoles turcas: solteiro, secular e moderno, um playboy. Vive sozinho, sem laços familiares, sem amigos verdadeiros, sem esposa e sem filhos, trazendo as mulheres com quem sai para sua casa, um apartamento luxuoso num condomínio moderno. Meryem tem sentimentos por ele, mesmo sabendo que não há a mínima possibilidade de ter um relacionamento com ele. Por sua vez, Sinan sente admiração e atração por ela: muito provavelmente, pela pureza dela. Isto é notado quando ele chega a cheirar as roupas que a faxineira usa ao limpar a casa, as quais ficam guardadas num armário do banheiro.

A mãe de Sinan vive em um apartamento, no meio de muita bagunça, depressiva, sozinha. Ela espera atenção e carinho do filho, mas, por não receber, sempre reclama dele. No entanto, a série dá a entender que a falta seja recíproca, pois ele também sofreu com ausências da mãe: por exemplo, ela nem se lembra, não por esquecimento pela idade, mas por falta de atenção mesmo, se o filho ou o marido falecido gostavam de comida com carne moída, o que deixa claro o quanto ela está ou esteve distante de Sinan.

Este é um tipo de família que tem a riqueza que muitos sonham ter, mas não tem sentimentos, não tem emoção, não tem amor pela vida, pela família e pelas amizades. É triste dizer que a cada dia a quantidade desse tipo de "família" aumenta, não só na Turquia, mas em todo o mundo. Nas grandes cidades, muitos vivem nos apartamentos, a um metro de distância do seu vizinho, mas muitas vezes nem sabem seu nome. Neste sentido, Sinan é uma demonstração de que ser rico e viver de forma moderna nem sempre são elementos suficientes para ser feliz.

\section{Duas classes em tensão}

Meryem tem atendimento para tratar de seus desmaios, num hospital público, pela psiquiatra Peri (Defne Kayalar). Peri representa "a maioria" entre a elite turca; secular, moderna, com estudos no exterior, é alguém que vê a vida que leva como "a vida normal", como se fosse a única opção correta. Em um dos episódios, Peri reconhece o preconceito que tem contra as mulheres de véu. Embora ela saiba que tal preconceito seja errado tanto pela sua profissão quanto por questões éticas e pessoais, não consegue impedir seus ressentimentos. Afinal, a formação que ela recebeu na família e no exterior, o ambiente e o círculo de amizades que ela possui cultivam a visão de que tudo o que está ligado à religião, à tradição significa antiguidade, atraso. A série mostra que Peri herdou muitos desses preconceitos da mãe. Em uma cena, quando a personagem está sentada no sofá na sala da casa dos seus pais, todos assistindo televisão, sua mãe reclama por ter visto uma moça com véu e diz que "Essas mulheres estão em todo lugar e ficam mostrando-as".

Uma das personagens que ajudam o espectador a conhecer Peri é Melisa (Nesrin Cavadzade), uma das amantes de Yasin e atriz popular das novelas turcas - e colega da psiquiatra nas aulas de yoga. Quando Melisa pergunta a Peri se há mulheres de véu em sua família, ouve a resposta: "Não, nós somos todas normais".

Tal pensamento sobre a "normalidade" se relaciona à questão da secularização da Turquia. Esta foi liderada por Mustafa Kemal Atatürk, o fundador da República da Turquia, após o fim do Império Otomano, como resultado da derrota na I Guerra Mundial. Um pouco antes da I Guerra, o Império já estava sofrendo com a perda de seus territórios e tendo problemas com a Revolta Árabe, mas após o conflito, o Reino Unido e a França, vitoriosos, dividiram os territórios árabes que faziam parte do território otomano. Foi o fim de uma longa dominação 
que chegou desde partes do Irã de hoje, no Leste, até Viena, no Oeste; da Ucrânia e Crimeia, no Norte, até o Egito, Argélia, Síria e Iraque, no Sul; ou seja, o Império administrou por muito tempo uma população de diversas etnias, culturas e religiões. Além disso, por ter sido o maior e mais poderoso país muçulmano, o Califado Islâmico (representação máxima dos muçulmanos) estava no poder do Sultão otomano. Isso mudou com a guerra. Atatürk, como líder militar que foi vitorioso na Guerra de Independência Turca contra as potências ocupantes, fundou a República da Turquia, como um país laico e democrático, abolindo a monarquia e o califado. Tomou medidas como mudar o alfabeto do árabe para o latino, ocidentalizar o ensino e a educação, restringir - praticamente proibir - o ensino religioso. Seu mandato aconteceu em um sistema unipartidário, desde a fundação da República em 1923 até a sua morte em 1938.

A elite turca, desde os tempos de Atatürk, foi à Europa, principalmente França, para estudar, conhecer o Ocidente, os valores ocidentais e laicos, e ocupou os postos mais importantes na administração pública ao voltar à Turquia. Até o começo do século XXI, isso continuou assim. Sempre que houve uma ascensão de partidos conservadores ou religiosos, o que representava uma possibilidade de mudança em relação ao sistema vigente, vieram à tona golpes militares e o sistema kemalista foi, deste modo, mantido. Essa situação só mudou com a subida de Recep Tayyip Erdogan ao poder. No entanto, o que inicialmente pareceu uma representação da vontade da maioria da população, em alguns anos se transformou numa evidência de que o autoritarismo mudara de mão, passando dos kemalistas aos islamistas.

Por isso, a polarização na sociedade turca não é algo novo. Uma parte (os religiosos, conservadores) vê a outra como infiel, desrespeitadora de valores e tradições, admiradora do Ocidente e dos valores ocidentais. Já a outra parte (os kemalistas, os ocidentalistas com um certo menosprezo à sua cultura, religião) enxerga a primeira a partir das ideias de atraso, retrocesso, subdesenvolvimento, ignorância dos valores ocidentais e modernos etc.

Em "8 em Istambul", pode-se dizer que as personagens Peri e Meryem representam muito bem essas classes, divisões entre elas, visões de uma sobre a outra. Peri é uma turca moderna, solteira, altamente qualificada, com experiências e estudos no exterior. Já Meryem é uma turca tradicional, solteira, com formação básica e não conhece nem outras cidades do país. Enquanto atende Meryem, Peri parece estar usando a paciente para tentar superar seu preconceito sobre a outra classe, sentindo talvez um pouco de inveja dela. Ao mesmo tempo, Meryem pode falar sobre si e seus problemas apenas com Peri, por não ter mais ninguém com quem fazê-lo. Ou seja, as duas personagens nutrem admiração e ressentimentos uma em relação à outra. Os encontros de Peri e Meryem são como aulas de experiência para estudantes de psicologia e psicanálise.

\section{Questão curda}

Peri tem supervisão de seus atendimentos com Gülbin (Tulin Özen), uma psicanalista profissional, filha de uma família curda. Embora a família dela seja da região Sudeste da Turquia, onde em geral há pouca formação, poucas oportunidades de crescimento pessoal e profissional e muita influência cultural e religiosa, Gülbin tem uma vida secular, não segue tradições e normas. A família conservadora se opõe ao estilo de vida dela. Ela e a irmã, com quem está em constante conflito, fazem menções à falta de atendimento e à discriminação do Estado turco na região Sudeste do país, onde mora a maioria da po- 
pulação curda. Um irmão com paralisia cerebral é um dos motivos de discussão, inclusive com confronto físico. Isso porque Gülbin decide tratá-lo com o uso de cannabis, o que não é comum, talvez até proibido no país, mas a irmã não gosta da ideia e rebate.

A questão curda na Turquia é um assunto polêmico e usado continuamente por políticos. Os curdos eram um dos povos que faziam parte da população do Império Otomano, como os armênios, árabes e gregos. Quando Atatürk fundou a Turquia, ele o fez como um país de conceito estado-nação, ou seja, a existência do país está fortemente relacionada ao povo turco. Por isso, a partir de então, as minorias, incluindo a maior delas, os curdos, começaram a ficar em segundo plano. Não tiveram (até hoje) direito a estudar na própria língua, praticar a sua cultura e rituais religiosos e sofreram discriminação nos serviços estatais. Isso fez com que a região Sudeste da Turquia, onde a maioria da população curda vive, tivesse baixos níveis de desenvolvimento em educação, investimentos públicos e privados, industrialização, empregabilidade e turismo. Embora essa região tenha as cidades mais antigas do mundo, como Sanliurfa e Antioquia, o turismo sempre esteve longe do desejado. Surgiram grupos armados, o mais conhecido PKK (Partido dos Trabalhadores do Curdistão), para lutar por um Curdistão autônomo no Sudoeste da Turquia e mais direitos para os curdos na Turquia. 0 grupo foi fundado em 1978 e a partir de 1984 começou uma extensa luta armada contra a Turquia, liderado por Abdullah Öcalan, preso desde 1999. Mas, pela forma violenta que atuaram com armas e ataques terroristas, perderam a razão pelas coisas que reivindicavam pelos curdos. Por décadas, a guerra entre o exército turco e esses grupos fez a região sofrer ainda mais. Muitas famílias perderam seus filhos, seja como soldados do exército turco, seja como membros do PKK.

Um dos meus sócios aqui no Brasil, no nosso restaurante de delivery de comida turca, é curdo e ouvi muitas histórias tristes dele sobre este assunto. Ouço o idioma curdo quase todo dia, quando ele fala com sua mãe e seus parentes na Turquia.

No que diz respeito ao enredo da série, as personagens de Gülbin e sua irmã Gülan fazem menções a todas essas questões, criticando indiretamente os militares (já que não poderiam criticá-los diretamente na Turquia). Em uma das conversas, Gülbin fala para a irmã que o chute dado na barriga de sua mãe grávida, 35 anos atrás, causara a doença do irmão. Novamente, entendemos essa mensagem subliminar sobre a opressão sofrida por curdos, a partir do exército turco e dos poderes públicos.

\section{0 entorno de Meryem}

Meryem mora na casa do seu irmão Yasin (Fatih Artman), com a cunhada em depressão Ruhiye (Funda Eryigit) e os sobrinhos, uma menina e um menino. 0 menino não consegue falar. Yasin é um homem do interior, conservador, mas não consegue achar um trabalho digno, por isso, mesmo sendo religioso, trabalha como segurança numa casa noturna. Por fim, Ruhiye é uma mulher traumatizada pela violência que sofreu na infância, na aldeia onde nasceu e cresceu. Seu trauma fez com que desenvolvesse uma depressão profunda e tivesse que passar a responsabilidade pelos cuidados da casa e de seus filhos para Meryem.

Yasin retrata bem o homem do interior, que se importa muito com o que os outros dizem e ama sua esposa e seus filhos, mas não consegue expressar isso a eles. Ele se casa com Ruhiye aceitando que ela foi violentada quando era criança. Porém, não fazia ideia de que, por conta da aflição causada pela experiência, Ruhiye entraria em depressão e viveria 
sob total silêncio, numa vida sem sentido, só olhando para o longe, pensando vagamente, sem fazer praticamente nada, às vezes orando - para a direção errada, o que causa brigas entre o casal.

É importante destacar que traumas como o que Ruhiye foi submetida são realidade em todos os países, inclusive os de maioria muçulmana. Acredito que não haja religião nem cultura que não condene a violência de um homem contra uma criança; ao mesmo tempo, homens violentos existem em todas as sociedades. Porém, ao fazer uma comparação entre a história da personagem com o contexto do Brasil, imagino que a reação aqui seria um pouco diferente. Na Turquia, tal violência é vista (nem por todos, mas por uma maioria) como motivo de vergonha para a mulher (enquanto deveria ser vergonha para o homem que comete o estupro), muitas vezes não é exposta e a menina acaba sem o apoio da família e de um psicólogo, o que, infelizmente, pode causar depressão, como a vivida por Ruhiye. Há pessoas ignorantes que, para "limpar" essa "vergonha", casam suas filhas com seus estupradores, o que é um absurdo. No caso do enredo da série, fica claro que a personagem poderia ter sofrido menos danos, se tivesse sido acolhida e tratada no tempo adequado, se não se sentisse culpada pelo que aconteceu e se o homem tivesse sido exposto e punido.

O conservador Yasin e o "playboy" Sinan representam dois tipos bem diferentes de homens turcos. Entretanto, eles mantêm muitas coisas em comum; ambos não conseguem expressar o amor que sentem. Yasin é um homem que nunca irá conseguir dizer "eu te amo" para sua esposa ou até para seus filhos. Pela forma que foi criado e pelas normas que o cercam, isso é algo difícil de acontecer, senão impossível. Da mesma forma, Sinan, embora seja um jovem graduado e moderno, nunca terá coragem de dizer o quanto gostaria de estar com Meryem, talvez até formar uma família com ela. Ele vê isso como impossível por causa das grandes diferenças sociais, que lhe parecem um enorme muro entre eles; por isso, se contenta em sentir o cheiro das roupas dela no banheiro.

Outro personagem masculino da trama é Ali Sadi Hodja (Settar Tanrioğen), o líder espiritual do bairro onde mora Meryem, uma área rural distante dos pontos centrais de Istambul. Ele é consultado pelos moradores sobre assuntos variados. Yasin é um dos moradores que faz consultas com o sheik (religioso que guia os muçulmanos e orações nas mesquitas) e orienta a irmã Meryem a fazer o mesmo. 0 Hodja de bom coração é querido e respeitado pelos moradores e tem uma família feliz, pelo menos aparentemente, até que perde a esposa durante uma viagem de férias com seu trailer à sua cidade natal e fica muito abalado.

Embora Ali Sadi seja um religioso tradicional, sua filha adotada Hayrunnisa (Bige Önal) sonha com uma vida mais secular, sob influência de colegas da faculdade. Ela usa lenço para agradar a sua família, mas, na realidade, isso não é o que quer para sua vida: é homossexual e gosta de música eletrônica, a qual escuta escondida em seu quarto, onde também se maquia, atenta para não ser flagrada pelo pai. No final da série, a jovem decidirá viver a vida como sonha, tirará o lenço e abandonará o pai - que não descobre sobre a homossexualidade da filha -, se juntando a sua namorada.

Ali Sadi Hodja tem um ajudante na mesquita, Hilmi, que é muito diferente do sheik, pois estuda ciências modernas, filosofia e fala muito, fazendo citações dessas leituras. Porém, essa pessoa falante fica muda quando vê ou está perto da Meryem, seu sonho como esposa. Ele fica tímido, hesita muito no que fala e acaba cometendo gafes por causa da 
ansiedade. Cenas como essa representam bem o que os homens e as mulheres conservadores passam nesses momentos. Para pessoas como esses dois se casarem e formarem uma família, outros deveriam ajudar, intermediar e incentivar.

\section{Uma reflexão final}

Em "8 em Istambul”, cada roupa, chinelo, sapato, música de fundo, iluminação, cenário é selecionado a dedo para levar o espectador para dentro da realidade de cada personagem e ajudá-lo a enxergar os conflitos socioculturais entre os diferentes segmentos da sociedade turca. As cenas da bela cidade de Istambul trazem um gosto a mais ao seriado.

A trama trata de complexas contradições e choques entre modernidade e tradição, religião e secularismo, desejos e normas culturais/sociais/religiosas, conservadores e liberais, além de demonstrar o existente preconceito entre esses grupos, a violência contra mulheres, a fé praticada ou simplesmente respeitada, submissão às normas, traumas e segredos mantidos em silêncio gritante em cada pessoa, família e costume na sociedade turca. Em muitos momentos, o espectador se sente obrigado a ter empatia, o que motiva uma forte reflexão sobre a necessidade de evitar fazer julgamentos precipitados sobre "o outro". Isso também deve forçar o espectador a refletir não apenas sobre o (talvez distante) contexto turco, mas também sobre a sociedade da qual faz parte. Eu mesmo fiz isso pensando nas realidades que testemunho no Brasil. Embora os brasileiros tenham vários pontos comuns, há um abismo entre classes no que diz respeito a riqueza, formação, cultura, religiosidade e qualidade de vida. Como as famosas novelas brasileiras retratam essas realidades do Brasil, as séries turcas distribuídas no mundo afora através das plataformas digitais, como Netflix, Amazon Prime, Disney Plus, entre outras, servem à promoção da cultura turca, apresentação de diferentes formas de vida dos cidadãos turcos, belezas do país e alguns dos problemas.

Como empresário, tive e tenho oportunidade de trabalhar com brasileiros de diferentes grupos sociais, culturais e religiosos. Além disso, tenho esposa brasileira, e por meio dela, uma grande família brasileira (sogros, cunhados, tios etc.), com quem tenho uma relação muito boa. Essas convivências me fizeram enxergar na sociedade brasileira complexidades semelhantes às que vi na série turca da Netflix.

No que concerne especificamente à trama turca, a polarização política, o abismo entre a elite e a classe média, o preconceito e até a hostilidade entre seculares e conservadores - acirrados ainda mais com o discurso discriminatório do presidente Recep Tayyip Erdogan, no poder desde 2002 - são apresentados de forma tão natural que o espectador começa a ver isso como "normal". No entanto, é preciso ressaltar que a Turquia tem sofrido importantes mudanças. Principalmente nos últimos seis anos, Erdogan conseguiu ganhar poder e se tornou um ditador exterminador dos direitos fundamentais, das liberdades básicas, da imprensa livre, da independência dos poderes, e por conseguinte, da democracia.

0 constante uso da religião por Erdogan para fins políticos vem causando uma grande transformação na Turquia, de um estado laico e secular a um estado -quase - confessional, islamista. Estou usando o termo islamista não para definir a religiosidade, mas sim o proveito político tirado da religião: fazer da religião o seu discurso político, aparecer como se fosse religioso, como se fizesse algo bom para a religião e para a religiosidade das pessoas. Mas, no fundo, isso causa o maior dano à própria religião. Pois a religião perde a sua essência nesse tipo de interpretação e uso indevido pelos políticos. 0 político 
não deve se meter na religião das pessoas, e deve apenas praticar a sua, se tiver uma. Eu sou um muçulmano praticante e não concordo com diversas coisas que Erdogan faz, vejo muitas ações dele como coisas não permitidas na religião, como pecaminosas e antiéticas. A trama menciona esses assuntos com um toque leve, até porque eu imagino que não poderia se aprofundar e criticar, por razões óbvias de perseguição e censura que poderia sofrer. Isso me deixa muito triste. Eu gostaria muito de ver que as séries turcas, os filmes turcos, as notícias na Turquia pudessem ser totalmente livres do medo e da censura. Certamente isso faria com que essas produções fossem ainda melhores.

Por fim, é certo que "8 em Istambul" provoca reflexões por parte de quem assiste. Motiva o espectador a ter empatia, pensar na sua família, no seu cônjuge, nos seus filhos, no seu colega, no seu vizinho, no seu empregado, e a observar seus sentimentos, medos e pensamentos, enxergando os pontos comuns e discrepantes. Pois, como no seriado, também na vida real as vidas de pessoas de diferentes classes sociais e culturas se entrelaçam, todos convivem e formam a sociedade. 0 Brasil era um ótimo exemplo dessa convivência. Digo "era", pois, infelizmente, o Brasil está perdendo esse grande valor que tinha na sua sociedade. As pessoas que torcem para times adversários no futebol, que têm posições políticas diferentes, que têm práticas religiosas ou formas de vida diferentes conseguiam discutir, conversar. Nos últimos anos, talvez acompanhando o cenário mundial, a polarização vem aumentando e essas conversas não são como antes, ao ponto das pessoas sentirem cada vez mais necessidade de combinar a não entrar em assuntos polêmicos, principalmente políticos, para não criar desconforto nos encontros.

Espero que as coisas mudem, aqui no Brasil e lá na Turquia. E que o Brasil volte a ter aquela convivência exemplar, agradáveis bate-papos entre amigos de diferentes posições políticas, times de futebol, religiões e classes sociais. E que a Turquia volte a ter democracia, com a independência dos poderes, imprensa livre, academia sem influência, laicidade no sentido da separação entre religião e estado, garantia de direitos fundamentais a todos os cidadãos. 